\title{
Looking forward in operations management research
}

\author{
Danny Samson ${ }^{1} \cdot$ Matteo Kalchschmidt ${ }^{2}$
}

Published online: 8 March 2019

(C) Springer Science+Business Media, LLC, part of Springer Nature 2019

As we take over the Editor in Chief roles of the Operations Management Research journal, we want to look very briefly back and then cast our thoughts and aspirations for the field and the journal forward over the next few years and indeed decade.

First, we want to acknowledge the superb start that was provided to the OM Research community of researchers and professionals by Jack Meredith who so effectively founded this journal. Starting a new journal from scratch is a daunting task indeed, and many fail to take off and gain traction, yet Jack has accomplished this in OMR going from zero to becoming a real up and coming journal in our field, which is much needed. More recently, Scott Shafer and Jan Olhager have built it strongly, as measured by all the usual metrics. Yet there is still a lot to do in building OMR and contributing to our field.

Looking forward, we want this journal to contribute to both theory and practise in the field of Operations Management. Ours is a practical field, and our research should primarily serve those who put it into practise and respond to the many challenges that professional operations managers face. We welcome article submissions on any topics within or closely related to operations management. This is a dynamic field ever driven by new problems and challenges, that present new opportunities for research on a continuing basis. Some of these that we need to be collectively working on include:

1. The central question of operations and how it contributes to overall organisational effectiveness is still not fully understood. For example, there is still much that we do

Danny Samson

d.samson@unimelb.edu.au

Matteo Kalchschmidt

matteo.kalchschmidt@unibg.it

1 Department of Management and Marketing, University of Melbourne, 10th Floor, 198 Berkeley St, Carlton, VIC 3010, Australia

2 University of Bergamo, Bergamo, Italy not know about the interplay of primary competitive dimensions of cost, quality, flexibility, delivery, service, agility, innovativeness and others. We also need to support the debate about the strategic role of operations in any organization's success, that since the seminal works of this discipline have challenged us as operations scholars.

2. Beyond the operations of a single organisation, we have recognised over the past two decades that there is much value to be gained through improving the design and operations of supply networks. In this context, there is much more detailed knowledge to be gleaned through rigorous research about the structural elements of supply chains, and then the 'softer' elements, of relationships, trust and other issues. Modelling and empirical studies still tend to look at small subsets of supply chain design matters, and while this is necessarily so, much more work is required on whole of supply chain strategies.

3. Most organisations engage in improvement initiatives in good faith, and they spend significant time and money on these things, such as Lean, Six Sigma, business process reengineering, quality improvement, and many others. We know that in practice, the success rates of such initiatives is quite low, yet a minority of these initiatives can lead to great improvements, and we call for further definitive work as to the details of 'What Works', and the accompanying details of how, where, when and why?

4. Operations occur within simple and complex organisations and the interaction between operations and organizational systems is a key issue when companies need to make things work. Topics like the role of people, the interaction between humans and machines, the organizational design of operations are central for companies that need to properly balance the complex trade-offs existing in any industry. Several theoretical backgrounds have been adopted to analyse the organizational and human side of operation, but we expect more contributions to guide managers in defining the proper structure for their specific business. 
5. The link between operations and technology is strong and complex. Today, advances in technologies such as analytics related to Big Data, artificial intelligence, blockchain and others are likely to move efficient frontiers ever forward, yet they contain challenges and limitations, and they will impact on competitiveness and organisational and supply chain effectiveness, such that there will be winners and losers from these factors. Technology strategies and their relationships with other elements of operations management require further investigations and proper guidelines for practitioner on how to conduct technological investments are ever more needed.

6. Sustainable development, which we interpret as the environmental and social / community outputs and outcomes of organisations, as well as their value-adding and financial outcomes have become increasingly important challenges for operations management. How does this manifest and what might be some best practices in terms of operations systems designs and supply networks, as measured by the objective functions of multiple stakeholders on multiple dimensions of value related to the 'triple bottom line'? Studies have included examinations of trade-offs and synergies of operations strategies and decisions across these multiple stakeholders and dimensions, yet much more is to be done in this increasingly important domain. Specifically, we need to help managers to overcome the typical trade-off between social/environmental sustainability and economic performance, proposing and demonstrating ways that can use sustainability as a resource also for gaining economic profitability.

7. Supply chain risks have been much researched and modelled, especially in the context of disruptive events, yet many and various sources of uncertainty associated with operations and supply are an ever present element, and more theory is needed that can guide practice, which fully integrates the uncertain factors that pervade all aspects of supply management.

8. We live in a global market and companies operate with extended operations that spread all over the world. While in the past this characteristic was mainly reserved to large multinational companies, today we see even small and medium enterprises that operate globally, with facilities distributed all over the world, operating with foreign partners and continuously adapting their global operations. We need to tackle these challenges and provide theoretically grounded support to companies.

9. The functional arrangements and joint optimisation of operations/ supply chain parameters and designs with other functions of the organisation are important to organisational effectiveness and outcomes. These other functions and activity streams include marketing, overall business strategy, R\&D and engineering, financial management, procurement, information systems, people/ capability management and others. Operations management effectiveness can be seen as a means to an end, in which it holistically integrates with other streams of work in the organisation, aiming to create the best overall result. New challenges and opportunities emerge when we observe operations through the lenses of other functional units, thus more research, theory and best practice development is much needed in these domains.

10. While there is challenge enough in designing, conducting and improving operations that produce today's products and services, more research is needed into how innovation functions and activities can be integrated into operations systems designs. More broadly, innovation that can include new or enhanced products processes, technologies and business models all present challenges and opportunities for operations managers, who may strive for stable operations on one hand, yet must have the absorptive capacity to take in new ideas and effectively scale up all types of innovations. Concepts such as ambidexterity and innovation capability that relate to operations management require more theory and evidence based practice validation.

11. Whereas the history of operations management is based in disciplines including industrial engineering, that mainly tackled optimisation problems related to the manufacturing sector, there is a much less mature body of knowledge related to service organisations, even though they comprise the majority of economic activity in many economies. Adaptation of theory and practice to sectors such as health care, professional services, government operations, non-profits and the specific problems of many other sectors and industries bring a wealth of topics that merit further research.

12. Operations management research has important policy implications and public policy decisions have important effects on operations. We need to raise the bar from the managerial to the policy implications, providing guidelines to policy makers about the effect of decisions at national and cross-national level on companies' competitiveness. A lot of work has to be done here.

13. Researchers are always looking for new problems and challenges and keep on looking for new, unexplored research topics. Sometimes, we forget that even consolidated knowledge and solutions can be challenged by time and may require revision and adaptation. Replication studies are complex entities since their outcome in terms of publication is sometimes uncertain and thus limits the willingness (in particular of young scholars) to invest time and resources. We believe that proper revision of consolidated topics is still a promising 
area of research, where new insights can come out and new perspectives can be provided.

14. Finally, operations management is in need of more and better theories and research methods. The operations function and activities are central to most organisations and economies, yet we are not long on theoretical richness and perspectives, and new research methods that can shed new insights on 'What Works' well in operations would also be welcomed by both scholars and professional operations managers. Operations have benefitted much by the application of theories developed in other fields and new insights can be gained by adopting new theoretical lenses to interpret the phenomena we observe every day. Similarly, this field is in need to experiment with new research methodologies to tackle the new perspectives that are challenging us as operations scholars. We can learn a lot by observing other fields of study and adapt to our case what has been effective somewhere else, but at the same time we need to stimulate the development of new theoretical lenses and research methods that are specific for our purposes.
We will welcome article submissions that contribute to theory and practice on any topics related to operations management, certainly not limited to those described above, using any rigorous approach and methods. We believe that operations management is an applied field where works need a proper empirical application or modelling approach. For this reason, we welcome works with a strong empirical background either in the methodology and (more important) in their application. This doesn't limit our attention only to works that apply empirical research, since we welcome also theoretical papers as long as they tackle problems that have a clear managerial concern. We are considering the potential for special issues of this journal on important topics, as well as general articles. We welcome well-formed proposals for such.

Publisher's note Springer Nature remains neutral with regard to jurisdictional claims in published maps and institutional affiliations. 